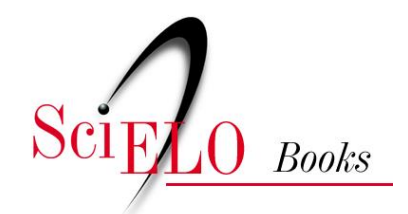

EDUFU

\title{
10 - A relação do aspecto com a voz, o tempo e o modo verbal
}

\author{
Luiz Carlos Travaglia
}

\section{SciELO Books / SciELO Livros / SciELO Libros}

TRAVAGLIA, L.C. A relação do aspecto com a voz, o tempo e o modo verbal. In: $O$ aspecto verbal no português: a categoria e sua expressão [online]. 5th ed. Uberlândia: EDUFU, 2016, pp. 275-288. ISBN: 978-65-5824-014-3. https://doi.org/10.7476/9786558240143.0012.

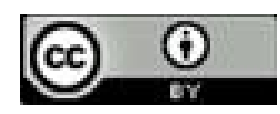

All the contents of this work, except where otherwise noted, is licensed under a Creative Commons Attribution 4.0 International license.

Todo o conteúdo deste trabalho, exceto quando houver ressalva, é publicado sob a licença Creative Commons Atribição $\underline{4.0}$.

Todo el contenido de esta obra, excepto donde se indique lo contrario, está bajo licencia de la licencia $\underline{\text { Creative Commons }}$ Reconocimento 4.0. 


\section{0 - A relação do aspecto com a voz, o tempo e o modo verbal}

\section{1 - RelaÇão eNTRE ASPeCto E VOZ}

Comrie (1976, p.84) afirma que em muitas línguas Indo-Europeias há interrelações entre aspecto e voz, e exemplifica tais inter-relações mostrando haver várias línguas em que a expressão clara de certos aspectos está restrita a uma determinada voz. No Russo, por exemplo, a expressão clara do perfeito só é possível na voz passiva.

Até onde pudemos verificar, o único aspecto que no Português apresentaria uma restrição com relação à voz é o não começado que não pode ser expresso nas vozes passiva $^{1}$ e reflexiva. Todos os demais aparecem tanto na voz ativa (como já foi sobejamente exemplificado) quanto na passiva e reflexiva, como se pode ver nos exemplos (1.381) a (1.399), em que as frases b são sempre de voz reflexiva e as demais de passiva.

1.381. a - Todos os dias pessoas são mortas sem razão, e ninguém faz nada para melhorar este trânsito. (imperfectivo, não acabado, habitual).

b - Todos os dias papai lava-se no tanque antes de entrar em casa. (imperfectivo, não acabado, habitual).

1.382. As casas naquele lugar eram feitas de madeira. (imperfectivo, não acabado, habitual).

1.383. Embora normalmente os clientes sejam avisados, nem todos respondem a nosso comunicado. (imperfectivo, não acabado, habitual).

1.384. a- A casa está sendo pintada com tinta lavável. (imperfectivo, cursivo, não acabado, durativo).

b - Maria está se penteando no meu quarto. (imperfectivo, cursivo, não acabado, durativo).

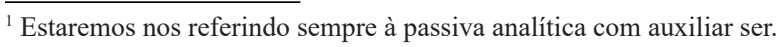


1.385. O menino estava sendo procurado por todos. (imperfectivo, cursivo, não acabado, durativo).

1.386. a - A terra é iluminada pelo Sol. (imperfectivo, não acabado, indeterminado).

b - Ninguém se lava com soda. (imperfectivo, não acabado, indeterminado).

1.387. A terra é dividida pelo Equador em dois hemisférios. (imperfectivo, não acabado, indeterminado).

1.388. a - A árvore foi cortada com serra. (perfectivo, acabado).

b - Ele veio chorando, porque tinha se ferido com a faca. (perfectivo, acabado).

1.389. A casa fora encerada no dia anterior. (perfectivo, acabado).

1.390. a - O ouro foi sendo roubado aos poucos. (perfectivo, durativo). b - João foi se limpando enquanto falava comigo. (perfectivo, durativo).

1.391. a - Meu filho tem sido convidado para muitas festas. (imperfectivo, não acabado, iterativo).

b - Desde que fez plástica, Maria tem-se contemplado seguidamente no espelho. (imperfectivo, não acabado, iterativo).

1.392. Se a relação das mercadorias andasse sendo alterada, seriam todos despedidos. (imperfectivo, não acabado, iterativo).

1.393. Seu relógio foi achado. (perfectivo, pontual, acabado).

1.394. a - Naquele instante, o remédio para o câncer fora descoberto. (perfectivo, pontual, acabado).

b - Maria feriu-se com a faca. (perfectivo, pontual, acabado).

1.395. A construção está sendo iniciada. (imperfectivo, começado, inceptivo).

1.396. a - Os tacos estão começando a ser lixados para passar sinteco. (imperfectivo, começado, inceptivo).

b - Sérgio está começando a lavar-se. (imperfectivo, começado, inceptivo).

1.397. A colheita está sendo terminada. (imperfectivo, não acabado, terminativo).

1.398. a - Os suspeitos estão terminando de ser interrogados. Só então poderemos dizer algo. (imperfectivo, não acabado, terminativo). b - Celina está terminando de pentear-se. (imperfectivo, não acabado, terminativo). 
É interessante notar que, na passiva, quando o auxiliar ser está no presente e pretérito imperfeito do indicativo e do subjuntivo, há uma tendência para o habitual, embora possamos ter o cursivo e o durativo. Estes aparecem se a forma verbal é usada numa descrição simultânea (cf. exemplos 1.254 e 1.399).

1.399. A árvore é balançada fortemente pelo vento. (imperfectivo, cursivo, não acabado, durativo).

Para indicação do cursivo e durativo nestes tempos, o falante prefere utilizar a perífrase "estar + gerúndio".

O aspecto pontual, cuja expressão já é pouco frequente na língua, parece ser expresso, nas vozes passiva e reflexiva apenas em frases como (1.393) e (1.394 a, b) com os pretéritos perfeito e mais-que-perfeito do indicativo e verbo indicador de situação estritamente pontual.

Os aspectos inceptivo e terminativo podem aparecer em frases como (1.395) a (1.398); mas frases de passiva como (1.396 a) e (1.398 a), apesar de possíveis, não são muito usadas e podem soar como um pouco estranhas.

O aspecto indeterminado é possível na voz reflexiva, mas muito pouco frequente.

\section{2 - RELAÇÃO ENTRE ASPECTO E TEMPO}

No capítulo 7, estudamos a expressão do aspecto pelos tempos flexionais. Aqui comentaremos a relação entre o aspecto e o tempo (= época).

Ao estudar a expressão do aspecto pelas flexões verbais observamos que, quando estas tinham valor de presente ou passado, havia atualização de aspecto, mas não quando tinham valor de futuro.

No item 7.2, vimos que o presente do indicativo não indica aspecto quando usado com valor de futuro (caso a, exemplos 332 a 335). Também nos casos d (exemplos 341 a 343) e e (exemplos 344 a 346) de não atualização do aspecto com o presente do indicativo, podemos atribuí-la ao valor de futuro que ali aparece. Podemos ver no item 7.3 que, nos dois casos em que o pretérito imperfeito do indicativo não expressa aspecto, o valor temporal é futuro (exemplos 405 a 408). No item 7.5, vimos que o futuro do presente e o futuro do pretérito (tempos flexionais que normalmente marcam o futuro) em si não expressam aspecto, só havendo atualização desta categoria pela atuação de outros recursos. Também no imperativo (cf. item 7.6) o valor temporal de futuro, ao lado da modalidade, bloqueia a atualização 
do aspecto. Com os tempos flexionais do subjuntivo, a categoria aspectual só se atualiza, se eles tiverem valor temporal de presente ou passado; pois com valor futuro estas flexões verbais não expressam qualquer noção aspectual (cf. no item 7.7 a exemplificação e os comentários feitos).

Apesar da restrição do futuro à atualização do aspecto, encontramos numerosos exemplos em que esta categoria se acha atualizada, apesar do valor temporal de futuro. Normalmente isto se dá pela atuação de certos recursos de expressão do aspecto, tais como as perífrases e os adjuntos adverbiais. Exemplos disto podem ser observados nas frases de números (433) a (437), (440), (441), (444 a 448), (591), (689), (693) e (739). Isto vem mostrar que o aspecto não é de todo incompatível com o futuro no Português. Adrados (1.954, p.261) advoga posição semelhante com relação ao grego, ao se opor à colocação de Ruiperez de que o aspecto em si é incompatível com o futuro.

Uma observação interessante a ser feita é que, quando temos aspecto com o tempo futuro, a situação apresentada como futura normalmente é presente ou passada em relação a uma outra situação (expressa em outra oração ou especificada no contexto), ou a um dado momento expresso por adjunto adverbial de tempo. Geralmente a situação futura é apresentada como presente a outra, se tivermos os aspectos imperfectivo e cursivo ou apenas imperfectivo (cf. exemplos 434, 457, $458,739,771,819$ e 1.400 a 1.408$)$ e como passada, se tivermos aspecto perfectivo (cf. exemplos 443, 591, 690, 693 e 1.409 a 1.412).

1.400. Quando ele estiver chegando, vocês poderão sair. (imperfectivo, cursivo, não acabado).

1.401. Quando ele chegar, eu estarei terminando de datilografar o relatório. (imperfectivo, terminativo, não acabado).

1.402. Às quinze horas eu vou estar estudando na casa da Raquel. (imperfectivo, cursivo, não acabado, durativo).

1.403. Estarei doente quando você vier. (imperfectivo, cursivo, não acabado, durativo).

1.404. Quando você chegar, o milho estará cozinhando. (imperfectivo, cursivo, não acabado, durativo).

1.405. Se o Paulo estiver dormindo quando você passar na casa dele, acorde-o. (imperfectivo, cursivo, não acabado, durativo).

1.406. Às seis horas terei a lição estudada.

a - S.R.: ter a lição estudada - imperfectivo, cursivo, não acabado, durativo.

b- S.N.: estudar - acabado. 
1.407. Terei o dinheiro, quando você vier. (imperfectivo, cursivo, durativo, não acabado).

1.408. Quando você vier me visitar, já serei presidente da firma. (imperfectivo, não acabado, indeterminado).

O aspecto no futuro com verbos simples só parece ser possível com verbos estáticos (exemplos 1.403, 1.407 e 1.408), ou com o auxílio de adjuntos adverbiais (exemplos 444 a 448).

1.409. Quando ele tiver chegado, vocês poderão sair. (perfectivo, acabado).

1.410. Eu terei terminado o trabalho, quando você voltar. (perfectivo, acabado).

1.411. Quando voltarmos, Edna já vai ter preparado o almoço. (perfectivo, acabado).

1.412. Quando o aviso chegar, ele já terá escrito a carta. (perfectivo, acabado).

Observe-se também que o futuro do pretérito, quando expressa aspecto, perde seu valor de futuro, tendo apenas a função de introduzir a noção modal de possibilidade (hipótese) em uma situação presente hipotética, se o aspecto for o imperfectivo (exemplos 439, 740, 756, 787, 820 e 1.413 a 1.416); ou em uma situação passada hipotética, se o aspecto for o perfectivo (exemplos 438, 690, 1.417 e 1.418). Este fato também ocorre com o futuro do subjuntivo, normalmente quando temos o verbo em oração introduzida por SE (cf. exemplos 743, 759, 790, 823 e 1.419 para o presente e o imperfectivo, e os exemplos 1.420 e 1.421 para o passado e o perfectivo).

1.413. Eu estaria passeando, se não tivesse que fazer este trabalho. (imperfectivo, cursivo, não acabado, durativo).

1.414. Eu teria a mesa posta, se as crianças não tivessem me atrapalhado tanto. (S.R.: ter a mesa posta - imperfectivo, cursivo, não acabado, durativo).

1.415. Eu possuiria muitos bens, se não tivesse sido tão imprevidente. (imperfectivo, cursivo, não acabado, durativo).

1.416. O vaso estaria sobre a mesa, se você não o tivesse tirado. (imperfectivo, cursivo, não acabado, durativo).

1.417. Eu teria terminado o trabalho, se vocês não tivessem me atrapalhado. (perfectivo, acabado). 
1.418. Aquele homem teria roubado minha carteira, se essa senhora não me avisasse. (perfectivo, acabado).

1.419. Se você estiver respirando bem, acho desnecessário fazer a operação. (imperfectivo, cursivo, não acabado, durativo).

1.420. Se meu filho tiver quebrado o vidro de sua janela mando colocar outro. (perfectivo, acabado).

1.421. Se Mariana tiver raspado a tinta velha, num instante faremos o trabalho. (perfectivo, acabado).

Vimos que o futuro do presente também perde o seu valor de futuro e passa a ter valor temporal de presente ou passado, se temos atualização dos aspectos imperfectivo ou perfectivo, respectivamente, sem que a situação indicada pelo futuro do presente seja presente ou passada em relação a outra situação ou momento futuro. Isto ocorre em frases como (929) a (931) e (1.422) a (1.426), normalmente de valor hipotético e sempre interrogativas.

1.422. Seu irmão não andará comendo escondido de vocês? (presente) (imperfectivo, não acabado, iterativo).

1.423. O que este homem estará procurando? (presente) (imperfectivo, cursivo, não acabado, durativo).

1.424. Seu tio não viverá se aproveitando da boa fé de vocês? (presente) (imperfectivo, não acabado, habitual).

1.425. Você não terá esquecido sua bolsa na casa de alguma amiga? (passado) (perfectivo, acabado).

1.426. O Flávio terá trazido o que lhe encomendei? (passado) (perfectivo, acabado).

Observe-se ainda que:

a. o presente do indicativo sempre marca aspecto imperfectivo, exceto quando marca o pontual e, em consequência, o perfectivo, nas condições especificadas no item 4.2.8;

b. o pretérito imperfeito do indicativo, único tempo flexional marcador de passado que expressa o imperfectivo, é na realidade um presente no passado;

c. os pretéritos perfeito e mais-que-perfeito do indicativo são marcadores de passado e sempre expressam perfectivo;

d. o presente do subjuntivo, quando tem sentido presente, sempre marca imperfectivo, exceto em frases como (1.427) - que raramente ocorrem - e se comporta aspectualmente da mesma forma que o presente do indicativo; 
1.427. Embora Pedro chegue na sala e descubra angustiado que sua mãe está morta, não solta um ai e não chora. (perfectivo, acabado).

e. o pretérito imperfeito do subjuntivo, quando tem sentido presente, sempre expressa o imperfectivo e, quando tem sentido passado, se comporta, em relação ao aspecto, de maneira semelhante ao pretérito imperfeito do indicativo, sendo também um presente no passado;

f. o futuro do subjuntivo, quando tem valor de presente, expressa o imperfectivo.

Diante de tudo o que já foi dito, podemos estabelecer as seguintes conclusões no que diz respeito à relação entre o tempo e o aspecto:

1. quanto temos o presente ou o passado, o aspecto se atualiza normalmente, sem qualquer restrição e pela ação de qualquer meio de expressão;

2. o futuro normalmente restringe a atualização dos aspectos e nenhum deles se atualiza neste tempo apenas pela ação da flexão temporal. Há sempre a ação de um dos seguintes meios de expressão: perífrases, semantema do verbo, adjuntos adverbiais e a repetição do verbo;

3. os aspectos imperfectivo e perfectivo só se atualizam no futuro, se a situação futura for respectivamente presente ou passada em relação a outra situação futura ou em relação a um momento futuro dado;

4. o imperfectivo aparece sempre ligado ao tempo presente que pode ser absoluto ou relativo ${ }^{2}$, pois, se a situação for passada ou futura, teremos sempre um presente relativo;

5. o perfectivo aparece sempre ligado ao tempo passado, exceto quando junto com o pontual no presente. O passado pode ser absoluto ou relativo, pois, se a situação for futura, teremos sempre um passado relativo;

6. o cursivo também parece se atualizar apenas quando temos o presente, seja este absoluto ou relativo; entretanto, isto pode se dever ao fato de que este aspecto só aparece ao lado do imperfectivo.

Vimos que o futuro restringe a atualização do aspecto, embora não a impeça de maneira total. Qual seria a razão desta ação restritiva do futuro?

\footnotetext{
${ }^{2}$ Estamos chamando de tempo absoluto aquele estabelecido em relação ao momento da fala, e de relativo o estabelecido em relação a um tempo absoluto ou em relação ao momento de ocorrência de outra situação da seguinte maneira: sejam as situações A e B. Se A é simultânea a B então A é presente a B. Se A é anterior a B então A é passada em relação a B.
} 
Castilho (1967, p.109) afirma que as muitas funções modais do futuro restringem a sua atuação na expressão do aspecto, e que este só aparece quando as funções modais se neutralizam.

O futuro realmente tem uso modal, podendo introduzir a modalidade de intenção (cf. item 10.3). Poder-se-ia pensar que a hipótese (probabilidade) aparece com o futuro, quando aparece com o futuro do presente (tempo flexional) em frases como (929) a (931), (1422) e (1424) a (1426). Contudo vimos que, neste caso, não temos o futuro, mas sim o presente ou o passado. A hipótese aparece no futuro quando temos o futuro do pretérito.

Luft (1976, p.131) coloca que, na verdade, não haveria um tempo flexional futuro, mas sim locuções de "infinitivo + haver" do tipo:

$$
\begin{aligned}
& \text { cantar }+ \text { hei } \\
& \text { cantar }+ \text { hia }
\end{aligned}
$$

com aglutinação na pronúncia representada na escrita: cantarei, cantaria. $\mathrm{O}$ futuro teria uma semântica de decisão, projeto, hipótese (valores modais), derivada de "haver" e a ideia de futuro seria uma implicação secundária de que planos, decisões etc. se projetam no futuro.

A colocação de Luft tem fundamento na história da língua, já que os nossos chamados futuro do presente e futuro do pretérito tiveram origem nas perífrases de "infinitivo + haver"; contudo nosso pensamento é que, no estágio atual da língua, pode-se dizer que há um tempo flexional futuro. Nosso intuito, ao citar tais colocações, foi mostrar a provável origem do valor modal do futuro expresso por aqueles tempos flexionais, já que "haver" é um auxiliar modal (cf. item 10.3 e BECHARA, 1.977, p.112).

Comrie (1976), que trata do assunto de maneira geral sem se referir a nenhuma língua em especial, falando sobre tempo, também registra que "o chamado tempo futuro de muitas línguas tem valor modal, bem como o de tempo". Todavia este autor não atribui a tal valor o fato de o futuro restringir o aspecto, pois, à página 73, afirma que a razão da ausência de uma distinção aspectual bem marcada neste tempo pode ser o fato de o futuro, em muitas línguas, ser um tempo pobremente diferenciado, como um tempo distinto do presente. Esta não nos parece ser a causa da restrição do aspecto pelo futuro no Português.

Adrados (1.954, p.266, nota 12) registra a afirmação de Chantraine de que, em uma ação futura, não interessa grandemente destacar o aspecto. Esta seria uma razão pragmática para a restrição do aspecto pelo futuro. 
Pode-se facilmente observar, nas frases em que o aspecto se atualiza com o tempo futuro, que, frequentemente, o valor modal do futuro não se neutraliza quando o aspecto está atualizado neste tempo. Assim sendo, não se pode afirmar que seja só pelo valor modal que o futuro restringe a atualização do aspecto, pois se assim fosse, quando aquele estivesse presente, este não se atualizaria. Pode-se, entretanto, aventar a hipótese de que certos recursos de expressão do aspecto são capazes de contornar ou anular o efeito da modalidade sobre o aspecto.

Dissemos, no item 7.5, que o tempo futuro atribui à situação uma realização virtual, até certo ponto abstrata. Isto anularia ou enfraqueceria o aspecto que fosse atualizado, dificultando sua percepção, o que torna desinteressante atualizar a categoria. O falante só se empenharia em tal atualização, quando ela fosse consideravelmente necessária, para justificar a utilização de recursos fornecidos pela língua para superar o efeito da realização virtual atribuída à situação.

Sobre o efeito do valor modal ver-se o que dizemos no item 10.3.

A não atualização da categoria de tempo parece implicar também na não atualização do aspecto. Isto porque a não atualização do tempo, normalmente, só ocorre quando há a intenção de se referir apenas à situação em si, sem qualquer referência ao TEMPO envolvido na sua ocorrência.

\section{3 - RelaÇÃo ENTRE ASPECTO E MODO}

Em várias passagens, aludimos ao fato de que a modalidade ${ }^{3}$ restringe a atualização do aspecto e mesmo nos detivemos neste particular, ao falarmos da expressão do aspecto pelas flexões verbais do subjuntivo.

Castilho (1.967, p.108) anota que, embora não se possa falar de incompatibilidade, observa-se que as noções aspectuais nem sempre ocorrem simultaneamente às noções de volição, possibilidade e intenção. Estas são, sem dúvida, noções modais.

Por modalidade entende-se a designação, na frase, da atitude do falante com relação ao seu próprio enunciado, a explicitação da atitude psíquica do falante em face da situação que exprime.

São as seguintes as noções modais:

\footnotetext{
${ }^{3}$ Preferimos aqui utilizar o termo modalidade no lugar do termo modo, visto que este está comprometido com os "modos gramaticais" (indicativo, subjuntivo e imperativo), mas os dois termos são usados frequentemente como sinônimos. Os "modos gramaticais" são apenas um dos meios de marcar a modalidade que pode também, por exemplo, ser marcada por advérbios (talvez, provavelmente, que marcam dúvida), ou uma oração principal com verbos do tipo de crer, proibir, temer, ordenar, e até mesmo pela entonação como afirma Bally (1942, p.10). (BALLY, C. Syntaxe de la modalité explicite. Cahiers Ferdinand de Saussure, Geneve, v. 2, p.3-13, 1942.).
} 


\section{1 - Certeza}

Normalmente é expressa ${ }^{4}$ pelos tempos do indicativo (cf. como exemplos a quase totalidade das frases com o verbo no indicativo apresentadas neste trabalho e (1.428) abaixo).

1.428. Hélvio deu-me um quadro de presente.

\section{2 - Prescrição}

A prescrição pode ser:

a. ordenativa positiva ou negativa. A prescrição ordenativa negativa é a proibição. São expressas pelo imperativo (exemplos 1.429 a 1.431).

1.429. Lê este livro!

1.430. Leia este livro!

1.431. Não saia daqui!

b. aconselhativa. Expressa pelo auxiliar dever na segunda ou terceira pessoas na perífrase DEVER + INFINITIVO, ou pelo imperativo com entonação adequada. Exemplos:

\subsection{Deves ler este livro.}

1.433. Você deve lhe pedir desculpas.

1.434. Não beba que é ruim para a saúde.

\section{3) Obrigação}

É expressa pelo auxiliar ter na perífrase TER + DE + INFINITIVO. Exemplos:

1.435. Tenho de ler este livro.

1.436. Tens de ajudar teus irmãos.

1.437. Sérgio tem de prestar contas ao chefe toda tarde.

\section{4) Necessidade}

É expressa pelo auxiliar dever na primeira pessoa, pelo auxiliar precisar em qualquer pessoa, nas perífrases PRECISAR ou DEVER + INFINITIVO (exemplos

\footnotetext{
${ }^{4}$ Não fizemos um levantamento exaustivo das formas de expressão das modalidades aqui expostas. Assim sendo, as formas de expressão registradas são as mais comuns e frequentes na língua. Além das que citamos no item 10.3, vejam-se também as apresentadas no item 7.7, bem como toda a exemplificação apresentada neste último.
} 
1.438 a 1.440), ou por construções do tipo "é preciso ou é necessário + oração com verbo no subjuntivo ou infinitivo" (exemplos 1.441 a 1.443).

1.438. Devo ler este livro logo.

1.439. Preciso encontrar-me com seu irmão.

1.440. Você precisa se alimentar melhor.

1.441. É preciso estar alerta.

1.442. É preciso que você venha.

1.443. É necessário que você preste mais atenção.

\section{5) Volição}

Expressa por verbos como querer e desejar, usados principalmente como auxiliares, em perífrases com o verbo principal no infinitivo (exemplos $1.444 \mathrm{e}$ 1.445) e também pelo subjuntivo (exemplo 1.446).

1.444. Quero ler este livro.

1.445. Deseja comprar algo, meu rapaz?

1.446. Deus os proteja nesta difícil tarefa!

6) Intenção

É expressa pelo auxiliar haver na perífrase HAVER + DE + INFINITIVO (exemplo 1.447), ou pelo futuro do presente (exemplos 1.448 e 1.449).

1.447. Hei de passar no concurso.

1.448. Lerei este livro amanhã.

1.449. Comprarei um carro, para poder trabalhar mais facilmente.

É frequente a intenção vir ao lado da volição como em (1.447).

\section{7) Possibilidade}

É expressa pelo auxiliar poder na perífrase PODER + INFINITIVO (exemplos 1.450 e 1.451), ou por expressões do tipo "é possível + oração reduzida de infinitivo" (exemplos 1.452 e 1.453).

1.450. Posso ler este livro quando quiser.

1.451. Ele pode fazer isso melhor do que você.

1.452. É possível encontrar coisas muito boas nesta feira.

1.453. É possível ir de carro à aldeia? 
Normalmente, possibilidade + interrogação $=$ permissão. Exemplos:

1.454. Posso ler este livro?

1.455. Posso usar sua máquina de escrever?

A permissão e o consentimento, que são subtipos da possibilidade, também podem ser expressos por DEIXAR + INFINITIVO. Exemplo:

1.456. Papai deixou-nos ir ao cinema. (deu a possibilidade).

É importante observar que temos dois tipos de possibilidade: a correspondente a "ser exequível" ou "ter aptidão", que chamaremos de possibilidade - 1, e a correspondente a uma "hipótese", que chamaremos de possibilidade - 2. Esta aparece em exemplos tais como (438), (439), (468) a (471), (545), (565) e (566).

\section{8) Probabilidade}

É expressa pelo auxiliar dever na perífrase DEVER + INFINITIVO (exemplos 1.457 a 1.459$)^{5}$, ou por expressões de dúvida + subjuntivo (exemplos 1.460 a 1.463).

1.457. Devo estar aí lá pelas três horas.

1.458. Devo examinar seu caso ainda hoje.

1.459. Ele deve gostar disso.

1.460. Talvez ele venha amanhã.

1.461. É possível que o diretor ainda te atenda.

1.462. É provável que a fera não ataque ninguém.

Também a probabilidade pode ser de dois tipos: a correspondente a "ser exequível" (probabilidade -1) e a correspondente a uma "hipótese" (probabilidade -2). Esta aparece em exemplos tais como (539), (540), (546) e (1463) abaixo.

1.463. É provável que Célio esteja em casa agora.

\footnotetext{
${ }^{5}$ As frases com o auxiliar dever têm sempre duas interpretações: uma de necessidade, outra de probabilidade. Portanto os exemplos (1.438), (1.457) e (1.458) podem ter tanto a modalidade de necessidade quanto a de probabilidade. Somente o contexto nos permite saber se temos uma ou outra. É bom observar que uma frase como "Devem ser quatro horas." só terá uma interpretação de necessidade num contexto muito especial
} 
A fronteira entre probabilidade e possibilidade não é muito nítida, assim, frequentemente, se torna difícil decidir entre uma e outra.

Como se pode observar nos exemplos (1.429) a (1.462) e também nos exemplos (459) a (467) e (472) a (536), além de outros, quando certas modalidades estão presentes na frase, $o$ aspecto normalmente não se atualiza.

Podemos observar que a modalidade de certeza não restringe a atualização do aspecto. A possibilidade e a probabilidade só o fazem quando se atribui à situação uma realização futura, o que normalmente ocorre com a possibilidade -1 e a probabilidade -1, donde se conclui que a possibilidade -2 e a probabilidade -2 também não restringem a atualização do aspecto. Já a prescrição (ordenativa ou aconselhativa), a obrigação, a necessidade, a volição e a intenção quase sempre bloqueiam a atualização do aspecto e, dificilmente, aparecem com uma situação cuja realização não seja futura.

Como já dissemos no item 7.7, as modalidades que mais restringem a atualização do aspecto são, portanto, aquelas que pressupõem uma realização futura para a situação a que se aplicam. Por outro lado vimos, no item 7.5 e no item 10.2, que o futuro que também restringe a atualização do aspecto, normalmente tem valor e função modal que podem ser a causa de sua atuação restritiva. Parece que temos aqui uma questão do tipo da precedência do ovo e da galinha: certas modalidades restringem a atualização do aspeto por atribuírem à situação uma realização futura ou é o contrário? Além destas duas hipóteses, temos uma terceira: a de que seria a ação conjunta de modalidade e futuro que restringiria a atualização do aspecto. A resolução desta questão é algo que deixamos como sugestão para futuros trabalhos. Todavia fica claro que o futuro e algumas modalidades restringem a atualização do aspecto.

Uma outra razão que pode explicar a ação restritiva da modalidade é o fato de que há na noção modal uma imperfectividade inerente. Daí não se poder atualizar o aspecto para o verbo que expressa a situação a que a modalidade se aplica (cf. para exemplo 1.464 e 1.465).

1.464. Eu posso escrever uma carta. posso $\rightarrow$ tenho a possibilidade (imperfectivo, não acabado, cursivo, durativo).

1.465. Consertarei o ferro de passar hoje à tarde.

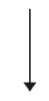

tenho a intenção de consertar (imperfectivo, cursivo, não acabado, durativo). 
A restrição do aspecto pela modalidade não é total, pois é comum encontrarmos, na língua, exemplos em que o aspecto se atualiza apesar da modalidade estar presente (normalmente possibilidade -2 ou probabilidade -2 , mas também outras). Quando isto ocorre, normalmente o aspecto é marcado por perífrases. Estas parecem ser o único recurso de expressão do aspecto capaz de anular o efeito da modalidade. Exemplos:

1.466. Você pode estar morrendo e não saber. (imperfectivo, cursivo, não acabado, durativo).

1.467. Ele parece ter estudado a lição. (perfectivo, acabado).

1.468. Vá separando o material para mim! (durativo).

1.469. Seu irmão deve andar matando aula. (iterativo).

Observe-se que, às vezes, o valor de futuro desaparece como em (1.466), (1.467) e (1.469), mas permanece em (1.468). Vejam-se também os exemplos (457) e (458), em que temos aspecto com a modalidade de prescrição ordenativa. Nestes dois exemplos a noção de futuro permanece, mas a situação é presente relativamente a outra situação futura especificada na oração adverbial temporal. 